\title{
Cost-Effectiveness Analysis of Active Surveillance Compared to Early Surgery in Small Papillary Thyroid Cancer: A Systemic Review
}

\author{
Han-sang Baek (D) \\ Chai-ho Jeong $\mathbb{D D}^{2}$ \\ Jeonghoon $\mathrm{Ha}^{\prime}$ \\ Ja-Seong $\mathrm{Bae}^{3}$ \\ Jeong-soo $\mathrm{Kim}^{3}{ }^{3}$ \\ Dong-Jun Lim (D) \\ Chul-Min Kim (D) ${ }^{4}$
}

'Division of Endocrinology and Metabolism, Department of Internal Medicine, Seoul St. Mary's Hospital, College of Medicine, The Catholic University of Korea, Seoul, Republic of Korea; ${ }^{2}$ Division of Endocrinology and Metabolism, Department of Internal Medicine, Uijeongbu St. Mary's Hospital, College of Medicine, The Catholic University of Korea, Uijeongbu, Republic of Korea; ${ }^{3}$ Department of Surgery, College of Medicine, The Catholic University of Korea, Seoul, Republic of Korea; ${ }^{4}$ Department of Family Medicine, Seoul St. Mary's Hospital, College of Medicine, The Catholic University of Korea, Seoul, Republic of Korea

Correspondence: Dong-Jun Lim Division of Endocrinology and Metabolism, Department of Internal Medicine, Seoul St. Mary's Hospital, College of Medicine, The Catholic University of Korea, 222, Banpo-daero, Seocho-gu, Seoul, 0659I, Republic of Korea

Email Idj6026@catholic.ac.kr

Chul-Min Kim

Department of Family Medicine, Seoul St. Mary's Hospital, College of Medicine, The Catholic University of Korea, 222, Banpo-daero, Seocho-gu, Seoul, 0659I, Republic of Korea

Email musofm@catholic.ac.kr

\begin{abstract}
Papillary thyroid microcarcinoma (PTMC) has indolent features and low mortality. Recently, active surveillance (AS) instead of early surgery (ES) has been introduced as one treatment option but economical preference has not been established. The study objective was to systemically review the literature relating to cost-effectiveness of AS compared to ES for PTMC. Keywords were selected through PICO (Population, Intervention, Comparison, and Outcomes) tools. The search was conducted using PubMed, Cochrane, EMBASE, and Elsevier databases. Papers that had irrelevant titles were written in foreign languages, or had no original results were excluded. Out of the 62 papers extracted, five relevant to the subject matter of this study were identified. Three papers made their own decision models and proceeded with cost-effectiveness analysis (CEA), but the remaining two simply compared costs rather than cost-effectiveness. In terms of cost-effectiveness, three papers preferred AS, one preferred ES, and one preferred neither. The major differences in the CEA might arise from variations in each country's medical insurance system, the utility score systems, and decision models used. In subgroup analysis, two papers preferred AS to ES for patients at a younger age at diagnosis in terms of cost-effectiveness as well as tumor biological characteristics. Although AS has been generally more cost-effective than ES in previous publications, younger age at diagnosis could be one factor contributing to preference for ES. The CEA of prospective cohorts based on the decision model and utility score for thyroid cancer should be undertaken to confirm the cost-effectiveness of AS.
\end{abstract}

Keywords: cost-effectiveness analysis, papillary thyroid cancer, quality of life, active surveillance, endocrine surgical procedures

\section{Introduction}

Although thyroid tumorigenesis is a complex process, most patients with differentiated thyroid cancer (DTC) exhibit slow tumor growth and have a good prognosis. ${ }^{1}$ In Korea, while the incidence of thyroid cancer has increased rapidly since 2000, the 10-year survival rate of $94 \%$ is relatively high according to the 2018 Korean National Cancer registration data. ${ }^{2}$ This trend is similar to that of worldwide data. ${ }^{3}$ Papillary thyroid microcarcinoma (PTMC) with a diameter of less than $1 \mathrm{~cm}$ progresses slowly, is less aggressive, and has been detected more frequently in recent years. ${ }^{4,5}$ Due to indolent features, low mortality of small thyroid cancer, and fear of surgical complications, active surveillance (AS) could be provided as a surrogate of early surgery (ES). In one meta-analysis about AS for PTMC, the maximum percentage of delayed operation in AS population was $32 \%$, but the reason for delayed operation was others rather than size increase or lymph node metastasis. ${ }^{6}$ And according to one retrospective study, the 
surgical complication rate was $1 \%$ for lobectomy and $17 \%$ for total thyroidectomy. ${ }^{7}$ However, it is vague that how these factors influence the cost-effectiveness of AS for PTMC. And it is not clear that AS is cost-effective compared to ES considering the good prognosis and long-term follow-up nature of DTC. This nature also makes it essential to consider cost-effectiveness from a long-term perspective for patients, physicians, payers, and the government. However, as it is difficult to find well-designed conclusive studies on the costeffectiveness analysis (CEA) of AS versus ES for PTMC in Korea and at a global level, a systemic review on the topic is necessary.

\section{Methods}

\section{Search Tools}

Keywords were selected through PICO (Population, Intervention, Comparison, and Outcomes) tools. The search was conducted using PubMed, Cochrane, EMBASE, and Elsevier databases. The selected keywords included "thyroid cancer patient" (population), "surgical management" (intervention), "active surveillance" (comparison), and "costeffectiveness" (outcomes). Detailed search words are shown in Table 1.

Using the aforementioned keywords, 62 papers were found. One of them was excluded as it was written in German. Four papers were found to be overlapping. Among the 57 remaining papers, 33 papers were excluded as they had unrelated or inapplicable titles. For example, the titles covered other cancers such as esophageal or lung cancer, or the papers did not include AS. Among the final

Table I PICO (Patient, Intervention, Comparison, Outcome) Method Keywords Used to Search the Literature on CostEffectiveness Analysis of Active Surveillance versus Early Surgery in Papillary Thyroid Cancer

\begin{tabular}{|l|l|}
\hline PICO & Keywords Used to Search the Literature \\
\hline P & $\begin{array}{l}\text { Thyroid cancer patient } \\
\text { Thyroid cancer (papillary, follicular, medullary, anaplastic) }\end{array}$ \\
\hline I & $\begin{array}{l}\text { Surgical management } \\
\text { Surgical management: Total thyroidectomy or lobectomy } \\
\text { with or without lymph node dissection }\end{array}$ \\
\hline C & Active surveillance (close observation) \\
\hline O & $\begin{array}{l}\text { Cost effectiveness comparison between two interventions } \\
\text { Comparison of cost-effectiveness of surgical management to } \\
\text { active surveillance; cost-effectiveness; including just sum of } \\
\text { costs (cost-effectiveness analysis, cost-utility analysis) }\end{array}$ \\
\hline
\end{tabular}

24 papers, 19 were excluded upon checking the abstracts, as they were reviews (Figure 1).

\section{Word Definition}

Cost-effectiveness analysis (CEA) is typically defined as a comparative assessment of two or more interventions in

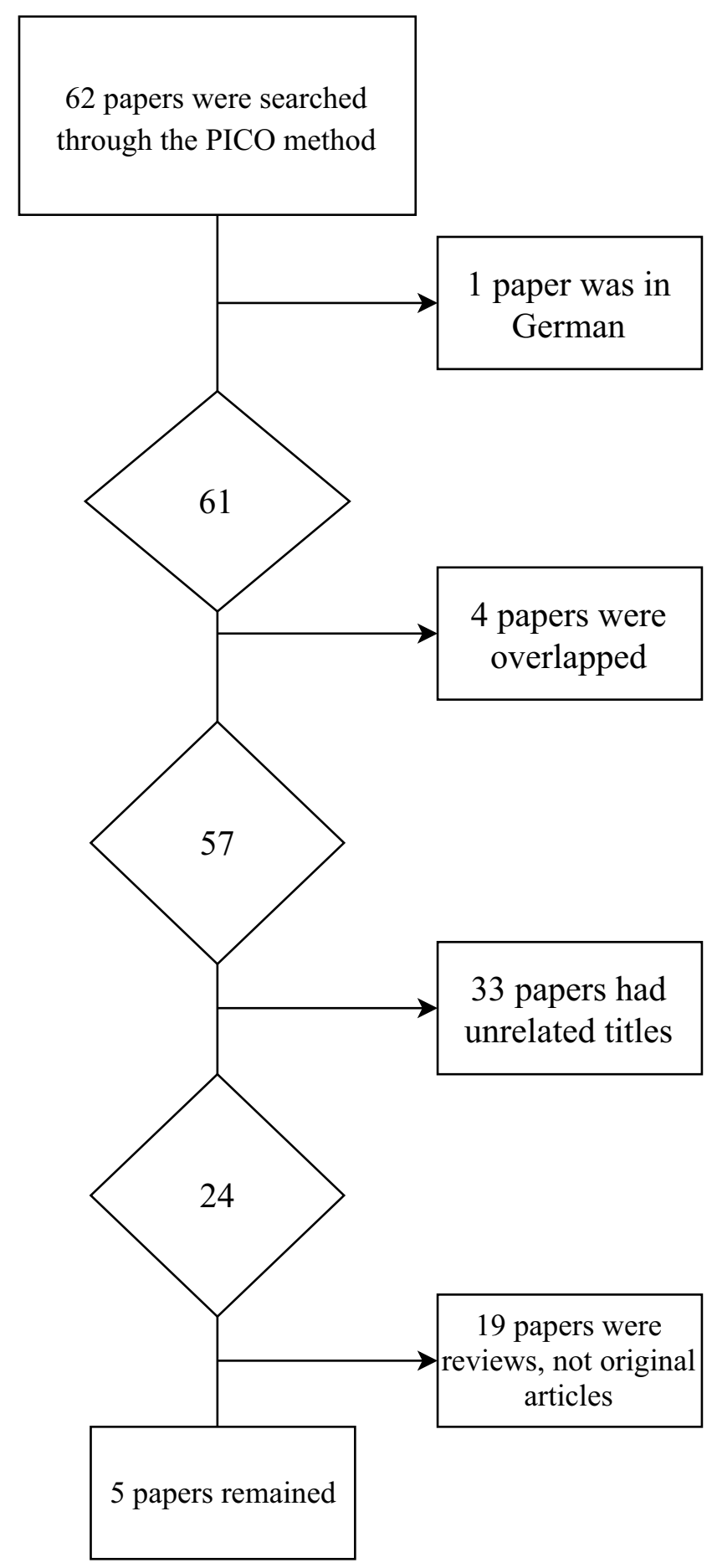

Figure I Among 62 searched papers, 5 papers were selected. Papers that had irrelevant titles, were written in foreign languages, or were review articles without original results were excluded. 
terms of costs and consequences. ${ }^{8}$ Medical procedures require heavy focus on the "consequences." For example, if a new antidiabetic agent is developed, its effectiveness is measured in terms of reducing blood sugar levels. For a CEA, quality-adjusted life-years (QALYs) are recommended to measure the appropriateness of the outcome after one medical intervention. This is called the utility score. For QALY, consequences can be measured by defining alive states as 1 (one year in perfect health) and death as 0 . QALY could be calculated in many ways. For one example, QALY data can be obtained from the quality of life (QoL) questionnaires answered by each patient. ${ }^{9}$ Furthermore, the incremental cost-effectiveness ratio (ICER) can be calculated using the following formula: ICER $=\frac{\Delta \operatorname{Cost}}{\triangle Q A L Y}$. ICER is defined as how much money is needed to obtain one QALY improvement by one medical intervention over one control care. If the medical intervention's ICER is less than a specific threshold (eg \$100,000/ QALY), this intervention is thought to be cost-effective.

The threshold of ICER is called willingness to pay (WTP). In 2001, the World Health Organization's Commission on Macroeconomics in Health suggested cost-effectiveness thresholds based on multiples of a country's per capita gross domestic product (GDP). Despite the controversy over a threshold based on GDP, a CEA study conducted in Korea set the threshold at approximately \$27,000-35,000/QALY. This varied remarkably from studies based on the USA, which usually raise the threshold to $\$ 50,000-100,000 / \mathrm{QALY}{ }^{10-14}$

When conducting a CEA, the analysis perspective being considered must be clarified. Five perspectives are generally cited: institution, third party, patient, government, and society. ${ }^{15}$ There are several types of costs used in performing the CEA. Direct medical costs include physician services, diagnostic tests, and hospitalization expenses. Direct nonmedical costs are expenditures due to illness (eg travel, accommodation), and do not include medical services. Indirect costs are defined as expenses arising from cessation or reduction of work productivity because of illness (eg, work loss and worker replacement). ${ }^{16}$

The two "decision models" most commonly applied in CEA are a decision tree and Markov model. In general, a decision tree consists of nodes and branches (Figure 2). Each node can represent decision options (such as whether to opt for a particular treatment) and it is connected to branches. The chance of following one branch versus another is decided by the probabilities of events estimated with data. ${ }^{17,18}$

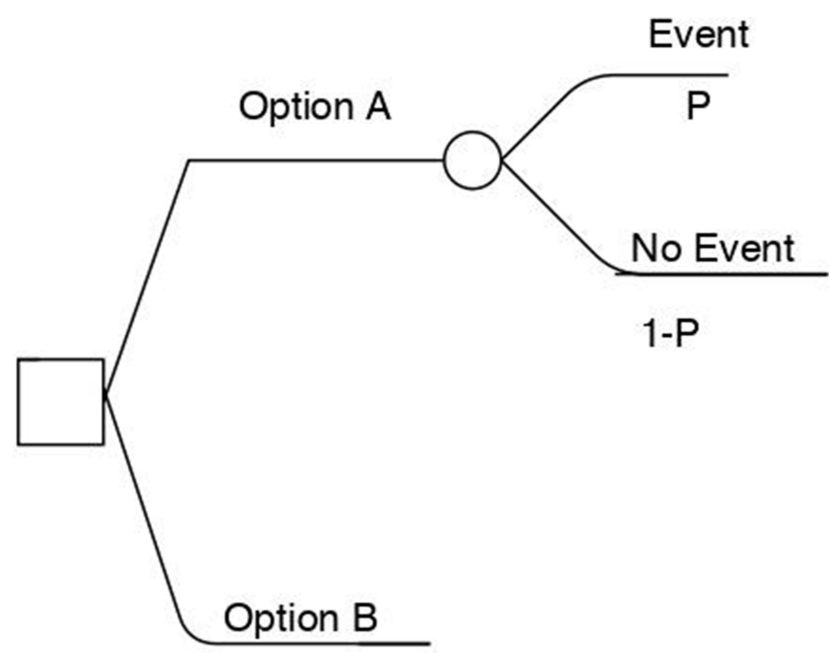

Figure 2 Decision tree example. Each node can represent decision options (such as whether to opt for a particular treatment) and it is connected to branches. The chance of going down one branch versus another is decided by the probabilities of events estimated with data. "P" represents the probabilities.

Notes: Adapted from: 201। Medical Economic Evaluation Guideline. Health Insurance Review \& Assessment Service (HIRA); 2016. Available from: http:// www.hira.or.kr/cms/participation/05/07/_icsFiles/afieldfile/2013/04/01/3.pdf. Korean. 2016 Copyright HIRA. ${ }^{31}$

A Markov model is a stochastic model used to deal with randomly changing systems (Figure 3). It assumes that future states depend only on the current state, not on the events that occurred before it. This assumption is called the Markov property. ${ }^{17,18}$

\section{Validation}

The CEA should be validated. In other words, the quality of a cost-effectiveness model should be measured. ${ }^{19}$ To validate results of the CEA and the quality of the CEA model used in each study, we adopted a grading system suggested by Chiou et al. ${ }^{20}$ They used a questionnaire consisting of 16 items to measure the model's construction, proper cost data adoption, and appropriate health outcome measures (Supplementary Table 1). Each question was answered dichotomously by yes or no to simplify the process.

\section{Results}

From the initial 62 papers, only five fit the criteria required by the current study (Table 2). Three papers made their own decision models and proceeded with CEA, but the remaining two papers simply compared costs rather than cost-effectiveness. All five papers only considered direct medical costs. Two papers clarified the perspective of analysis, but the others did not.

A study conducted by Lang et al in Hong Kong concluded that adopting AS was not only cost saving in the 


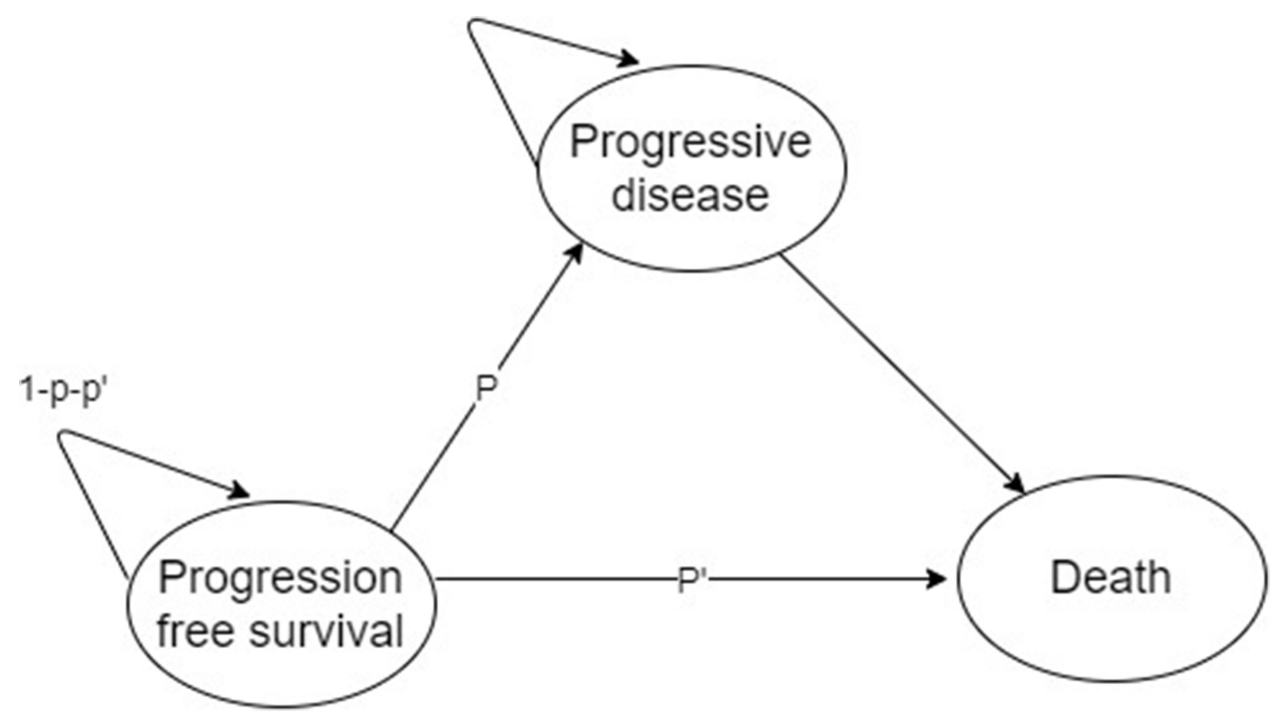

Figure 3 Markov model example. Each circle represents a specific medical condition. "P" represents the probability that a medical event can happen. Notes: Adapted from: 201 I Medical Economic Evaluation Guideline. Health Insurance Review \& Assessment Service (HIRA); 20I6. Available from: www.hira.or.kr. Korean. 2016 Copyright HIRA. ${ }^{31}$

initial 16 years but also remained cost-effective thereafter. $^{21}$ The authors constructed a decision tree and conducted a CEA on the base case hypothesis. They used cost data from public access files of the Centers for Medicare and Medicaid Services and examined the cost from an institution's perspective. Indirect costs were not included. Utilities and probabilities used for the decision tree were based on literature. They used QALY as a utility score to measure cost-effectiveness. In contrast to other studies, only three cases were scored: alive without permanent complication (1.00), alive with permanent complication (0.54), and death (0) (Table 3 ). The results showed that more money was spent on AS than ES (\$7204 vs $\$ 6521$ ) but also that more QALY was gained (15.23 vs 14.97) (Table 2). They set the WTP as $\$ 50,000 / \mathrm{QALY}$. ICER per patient for AS and ES was 473.1\$/QALY and 435.7\$/QALY, respectively, and both were lower than the WTP. As both the cost and QALY of AS were higher than those of ES, the authors calculated the incremental (AS minus ES) values of the base case to see if AS is really superior to ES in terms of cost-effectiveness. In this case, the ICER was 2623\$/QALY, which meant that AS was more cost-effective. In sub-group analysis, those under the age of 40 showed a larger ICER than those over 40 (11,501\$/QALY vs 1263\$/QALY), indicating that AS required more money to achieve the same QALY difference in those under 40 and they preferred ES over AS. Nevertheless, the ICERs of AS in both age groups were below the WTP threshold of $\$ 50,000$. This means adopting AS might not only be economic but also cost-effective regardless of patient age. The CEA structure was well organized and they used proper cost data. Despite the use of a simplified utility score system, the analysis and results were reliable (Table 4).

Venkatesh et al concluded that the cost-effectiveness of ES is highly dependent on patients' utility score differences. $^{22}$ They constructed the Markov model as a decision model, and the CEA was based on the case hypothesis. The authors determined the cost from the perspective of the third-party payer. Medical costs were obtained from published Medicare reimbursement rates as well as the Healthcare Costs and Utilization Project. They also used QALYs for the utility score calculated according to changes in QoL. However, they used the utility score for prostate cancer because there was no published literature on the utility of thyroid cancer at that time and prostate cancer is the only other solid cancer in which AS is an acceptable management option instead of ES (Table 3). The WTP was set at $\$ 100,000 / \mathrm{QALY}$. If a patient had small thyroid cancer that had not been removed by surgery (indicating AS), this would negatively affect QoL by "living" long-term with the diagnosis of a cancer and worsen the patient's utility score. When a health utility difference between AS and a disease-free state was smaller, AS was found less expensive than ES and provided more QALY. On the other hand, when the 


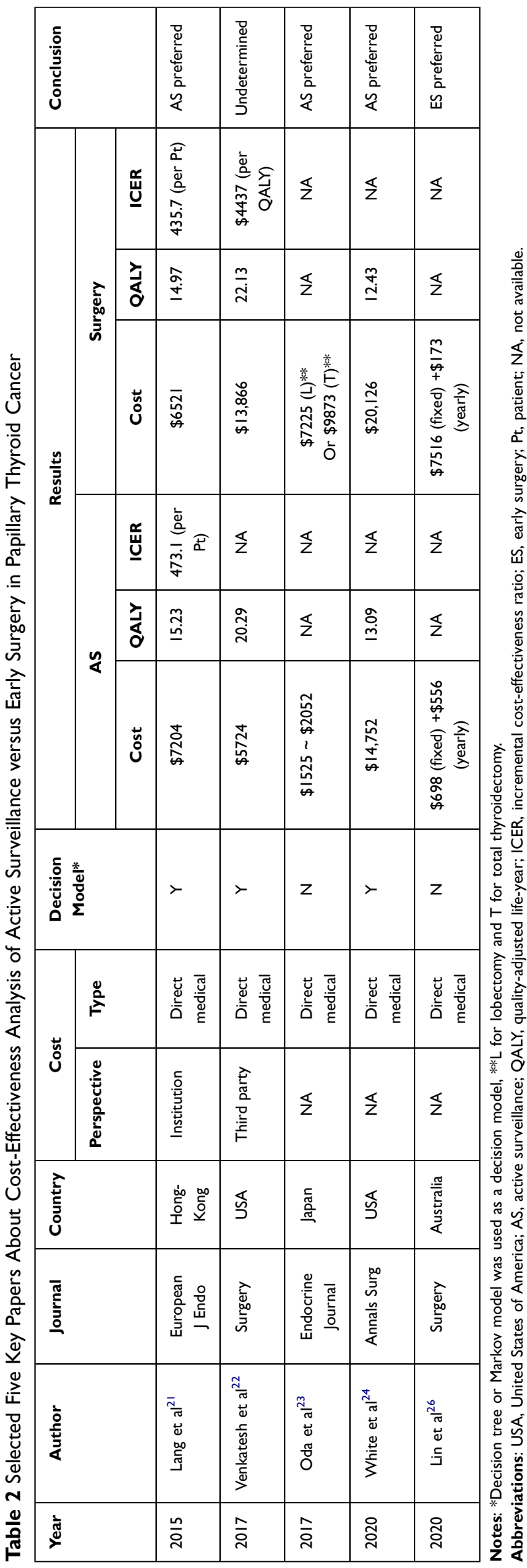

Table 3 Utility Score of the Three Key Reference Papers About Cost-Effectiveness Analysis of Active Surveillance versus Early Surgery in Papillary Thyroid Cancer

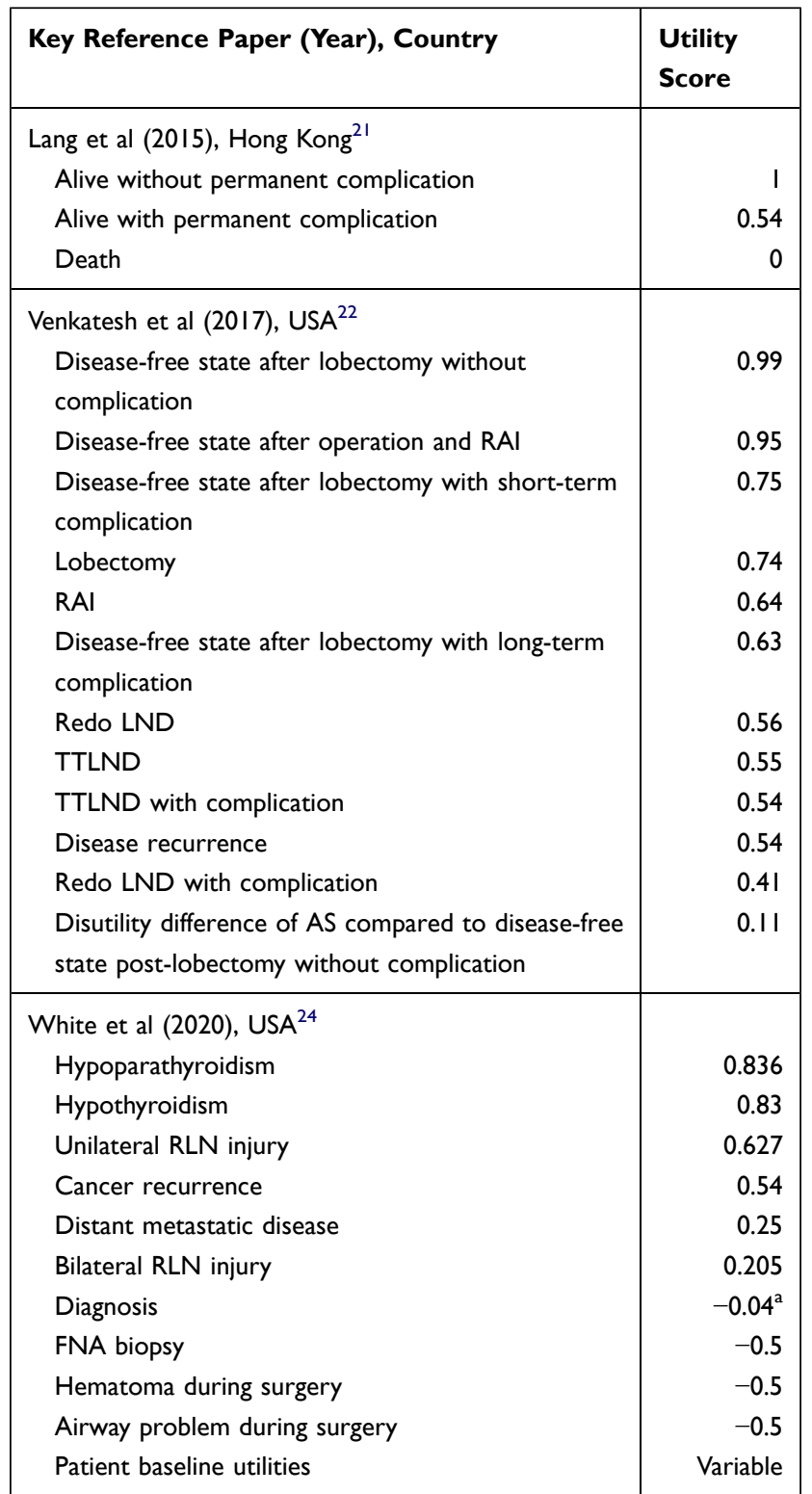

Notes: ${ }^{a}$ White et $\mathrm{al}^{24}$ estimated disutility and summed it into the patient's total lifetime utility score.

Abbreviations: RLN, recurrent laryngeal nerve; FNA, fine needle aspiration; RAI, radioactive iodine; LND, lymph node dissection; TT, total thyroidectomy.

health utility difference was larger between AS and a completely disease-free state, ES was cost-effective. Thus, they concluded that the cost-effectiveness of AS or ES was highly dependent on the patient's utility score, without preference for either. In terms of validity, the authors constructed a well-designed CEA model, and used proper cost data. Although they applied the utility score for prostate cancer, the justification for usage of it 
Table 4 Method of Modeling, Cost Sources, Utility Source, and Validation Level of Selected Papers

\begin{tabular}{|c|c|c|c|c|c|}
\hline & $\begin{array}{l}\text { Lang et al }(20 \text { I } 5 \text {, } \\
\text { HK })^{2 I}\end{array}$ & $\begin{array}{l}\text { Venkatesh et al } \\
(2017, \text { USA })^{22}\end{array}$ & $\begin{array}{l}\text { Oda et al } \\
(2017, \\
\text { Japan }^{23}\end{array}$ & White et al $(2020, \text { USA })^{24}$ & 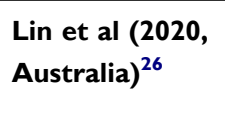 \\
\hline $\begin{array}{l}\text { Method of } \\
\text { modeling }\end{array}$ & Decision tree & Decision tree & None & Markov decision model & None \\
\hline $\begin{array}{l}\text { Cost } \\
\text { sources }\end{array}$ & $\begin{array}{l}\text { Public access file } \\
\text { from Centers for } \\
\text { Medicare and } \\
\text { Medicaid Services }\end{array}$ & $\begin{array}{l}\text { Publications of } \\
\text { Medicare } \\
\text { reimbursement rates } \\
\text { and the Healthcare } \\
\text { Costs }\end{array}$ & $\begin{array}{l}\text { Japanese } \\
\text { Health } \\
\text { Care } \\
\text { Insurance } \\
\text { System }\end{array}$ & $\begin{array}{l}\text { The fee schedule at a major academic } \\
\text { hospital, and Centers for Medicare and } \\
\text { Medicaid Services' National Inpatient Sample } \\
\text { database }\end{array}$ & $\begin{array}{l}\text { Royal North } \\
\text { Shore Hospital } \\
\text { and the University } \\
\text { of Sydney }\end{array}$ \\
\hline $\begin{array}{l}\text { Utility } \\
\text { source }\end{array}$ & $\begin{array}{l}\text { From authors' own } \\
\text { assumption }\end{array}$ & $\begin{array}{l}\text { Publications for } \\
\text { asymptomatic prostate } \\
\text { cancer }\end{array}$ & None & $\begin{array}{l}\text { Based on more than } 20 \text { studies of the QOL } \\
\text { of patients with PTC }\end{array}$ & None \\
\hline $\begin{array}{l}\text { Validation } \\
\text { level* }\end{array}$ & 13 & 14 & 6 & 12 & 5 \\
\hline
\end{tabular}

Notes: *The validation level was scored according to the criteria suggested by Chiou et $\mathrm{a}^{20}$ [Chiou et al. Development and validation of a grading system for the quality of cost-effectiveness studies. Med Care. 2003;4I(I):32-44]. The higher number indicates a more validated model with high reliability. See more details in Supplementary Table I. Abbreviations: USA, United States of America; QoL, quality of life; PTC, papillary thyroid cancer.

was given because utility score for thyroid cancer was not available at that time (Table 4).

Oda et al from Japan concluded that the total cost of ES was 4.1 times higher than that of $\mathrm{AS}^{23}$ Rather than a decision model, the authors created a model of the flow of thyroid cancer management. They used Kuma Hospital's patient data, which included an observational study of 2153 patients with PTMC. From the data, they calculated "the simple cost" of AS and ES and compared both. Whether conversion surgeries (for example, patients having a change of mind) were considered or not, the simple cost of ES was about 4.1 to 6.5 times the cost of AS (\$7225-\$9873 vs \$1525-\$2052) depending on the type of surgery and postoperative medication. The costs were calculated according to the Japanese Health Care Insurance System. The authors did not calculate the utility score; "cost-effectiveness" was not estimated. They used the prospective cohort population but they did not make the CEA model and did not use the utility score (Table 4).

White et al from the USA compared cost-effectiveness of the 2009 and 2015 American Thyroid Association (ATA) guidelines. The 2009 ATA guidelines suggested total thyroidectomy for malignant nodules of any size and lobectomy for very specific nodules: AS was not an option. On the other hand, under the ATA 2015 guidelines, small $(<1 \mathrm{~cm})$ solitary nodules with no lymph node metastasis could be managed with AS. The costeffectiveness outcomes showed that the ATA 2015 strategy was better than that of 2009 for ES. Specifically, ATA 2015 delivered greater QALY (13.09 vs 12.43) at lower cost $(\$ 14,752$ vs $\$ 20,126),{ }^{24}$ meaning that including the AS strategy brought better QoL at a lower price. The authors created a Markov simulation model and used cost data from the published literature, the Centers for Medicare and Medicaid Services Fee Schedule, the fee schedule at a major academic hospital, and the National Inpatient Sample database of the Centers for Medicare and Medicaid Services. They did not state the cost perspective. Complicated utility scores were used based on at least more than 20 studies of the QOL and diagnosis/treatment processes in patients with PTC. ${ }^{25}$ The authors presented a well-organized CEA model and clarified the cost data sources but not the cost perspective. They used the utility score derived from studies about thyroid cancer, not other kinds of malignancy (Table 4).

Lin et al from Australia concluded that ES might have a long-term economic advantage for younger patients who are likely to require more than 16.2 years of follow-up in an AS scheme. ${ }^{26}$ They used prospective surgical cohort data from between 1985 and 2017 and compared the total cost of surgical treatment to hypothetical AS. However, they did not use the decision tree or Markov model, and did not calculate the utility score. 
Therefore, the validity of their model is lower than the other studies (Table 4).

In short, from a cost-effectiveness point of view, three of the aforementioned studies preferred AS, one preferred $\mathrm{ES}$, and one did not prefer either.

\section{Discussion}

In light of high thyroid cancer incidence and little information on cost-effectiveness of treatment, the current study aimed to search and review studies relating to costeffectiveness of AS compared to ES for small PTC. In a mini-review of AS of PTMC in Korea, the authors insisted that the conclusions of CEA from one country with country-specific medical costs should not be applied to other countries but believed that ES might be more costeffective in Korea due to lower surgery costs. However, in the absence of cost-effectiveness data, it might be too early to reach that conclusion because the costs of physician visits and sonography are also lower in Korea. ${ }^{27}$

Because individual countries have varying medical cost systems, it was inevitable that the CEA results would be heterogeneous. Oda et al from Japan reported that the total cost of ES was 4.1 times higher than that of AS. However, the cost of thyroid sonography was only $\$ 32$, which is much cheaper than costs mentioned in other studies $(\$ 100-\$ 124)$. The physician visit fee was also cheaper than other costs $(\$ 20$ vs $\$ 96.96-117) .{ }^{21-24,26}$ On the other hand, the cost of surgery was \$2801-\$3165, which is similar to that of other studies (Table 5). As the AS costs mainly consist of thyroid sonography and physician visit fee, AS is deservedly costeffective in Japan. But it is not clear how much each medical cost contributes to the results. Although Korea and Japan share a similar medical cost system, it is not possible to conclude that the CEA results would also be similar.

Most importantly, the differences in the CEA of each study come from the utility score. Lang et al assumed that the utility of a healthy state in the model was 1 regardless of the degree of a patient's QoL, with only three semiquantitative categories. $^{21}$ On the other hand, Venkatesh et al divided the utility levels into more details, but they used the utility score from prostate cancer, not thyroid cancer $^{20,22}$ As the authors mentioned, because the population of thyroid cancer has a different age, sex, and QoL compared to that of prostate cancer, a separate utility score for thyroid cancer is needed for CEA. White et al used the utility score calculated from the study results based on the QoL of PTC patients. ${ }^{24}$ However, White et al compared the 2009 and 2015 ATA guidelines, not the actual AS and
ES. Therefore, future studies should attempt to develop a standard utility scoring system and apply it to studies that compare AS and ES.

Of the five papers, two created a decision tree and one a Markov model. However, they all created their own unique decision models. $^{21,22,24}$ This may cause confusion about whether the differences derive from the cost, the utility score, or the actual performance differences between ES and AS. The Markov model was used to compare the two guidelines, not specifically AS vs ES. On the other hand, the decision tree was created to reflect the clinical decision. Although there were minor differences, the three papers that developed the CEA model showed high validity.

In addition, variations in study results might derive from the differences between the decision tree and the Markov model. The decision tree seems logical but is not suitable for application to recurring events because of its linear fashion. However, it is better for generalizing and applying learned data. On the other hand, the Markov model can handle many clinical problems related to time, such as life expectancy or disease over time, but it is limited due to its assumption, the Markov property. In other words, the Markov model is memoryless. ${ }^{17}$ With a limited number of studies using CEA, the most suitable model for thyroid cancer remains uncertain. Therefore, a well-organized standard decision model for thyroid cancer is needed for CEA.

Although some studies have dealt with the costeffectiveness of AS, it is difficult to reach a conclusion because of the different ways the studies conducted the CEA. Considering this, future studies on the following subjects are needed.

First, a consistent decision model should be developed. Although heterogeneity inevitably derives from varying costs in different countries, a uniformly useful model, such as a Markov model or decision tree, is needed. Second, a utility score specific to thyroid cancer and a QALY system based on prospective cohort studies are needed. Lastly, appropriate follow-up and decision protocols for AS of thyroid cancer should be made. Although many studies on AS for PTMC have been conducted in recent years, tools for detecting disease progression have not been confirmed. ${ }^{27,28}$

Particularly, when the appropriate patients for AS are selected, age should be considered. In a multi-center cohort study in Korea, the risk of tumor volume increase in patients $<45$ years was twice higher than that of older patients during AS for low-risk PTMC. ${ }^{29}$ Besides, Lang et al showed that those under 40 years would prefer ES over AS based on sub-group analysis. ${ }^{21}$ This suggests that 
Table 5 Costs Mentioned in the Five Key Reference Papers on Cost-Effectiveness Analysis of Active Surveillance versus Early Surgery in Papillary Thyroid Cancer

\begin{tabular}{|c|c|c|c|c|c|}
\hline & $\begin{array}{l}\text { Lin et al }(2020 \text {, } \\
\text { Australia })^{26}\end{array}$ & White et al $(2020, \text { USA })^{24}$ & $\begin{array}{l}\text { Oda et al } \\
(2017, \text { Japan })^{23}\end{array}$ & $\begin{array}{l}\text { Venkatesh et al } \\
(2017, \text { USA })^{22}\end{array}$ & $\begin{array}{l}\text { Lang et al } \\
(2015, \mathrm{HK})^{21}\end{array}$ \\
\hline \multicolumn{6}{|c|}{$\begin{array}{l}\text { Initial diagnosis \& } \\
\text { follow-up costs }\end{array}$} \\
\hline AS & & & & $\begin{array}{l}\text { \$226 (AS) } \\
\$ 283 \text { (surveillance post- } \\
\text { lobectomy) } \\
\$ 431 \text { (surveillance after } \\
\text { post-operation RAl) }\end{array}$ & \\
\hline Visit to physician & $\begin{array}{l}\$ 117 \text { (visit to } \\
\text { endocrinologist) }\end{array}$ & $\begin{array}{l}\text { \$96.96 (primary care physician visit) } \\
\$ 145.72 \text { (specialist visit) }\end{array}$ & $\$ 20$ & & \\
\hline Blood test & $\$ 50$ & $\$ 23.1$ (serum TSH test) & $\$ 81$ & & \\
\hline US & $\$ 102$ & $\$ 124.86$ & $\$ 32$ & & \\
\hline FNA & $\$ 406$ & $\$ 497.78$ & $\$ 55$ & & \\
\hline CT scan & & $\$ 287.11$ & & & \\
\hline Medication & $\begin{array}{l}\$ 19 \text { (L-thyroxine) } \\
\$ 14 \text { (Ca \& vit. D) }\end{array}$ & $\$ 111.83$ (annual) & $\begin{array}{l}\text { \$34 (L-thyroxine) } \\
\$ 99 \text { (L-thyroxine } \\
\text { \& vit. D) }\end{array}$ & & \\
\hline \multicolumn{6}{|c|}{ Procedural costs } \\
\hline Thyroid surgery & $\$ 6428$ & $\begin{array}{l}\$ 12.178 \text { (neck dissection) } \\
\$ 9175 \text { (lobectomy) } \\
\$ 11,352 \text { (TT) }\end{array}$ & $\begin{array}{l}\$ 2198 \\
\text { (lobectomy with } \\
\text { PD) } \\
\$ 280 \text { I (TT with } \\
\text { CND) } \\
\$ 3165 \text { (CT with } \\
\text { MND) }\end{array}$ & $\begin{array}{l}\text { \$7967 (lobectomy) } \\
\$ 6482 \text { (Redo LND) } \\
\$ 9134 \text { (TTLND) }\end{array}$ & $\begin{array}{l}\$ 4513 \text { (lobectomy + } \\
\text { CND) } \\
\$ 6013 \text { (TT+CND) } \\
\$ 12,495 \text { (TT+CND + } \\
\text { selective neck } \\
\text { dissection) }\end{array}$ \\
\hline RAI & & $\begin{array}{l}\$ 6097.09 \text { (RAl) } \\
\$ 2103.80 \text { (thyrotropin injection) }\end{array}$ & & $\$ 451$ & \\
\hline \multicolumn{6}{|c|}{ Complication costs } \\
\hline Complications & & $\begin{array}{l}\$ 5790.24 \text { (airway problem) } \\
\$ 5790.24 \text { (hematoma) } \$ 1651.18 \\
\text { (hypoparathyroidism, annual) } \\
\$ 158.03 \\
\text { (hypothyroidism, annual) } \\
\$ 55,983.11 \\
\text { (Surgical mortality) }\end{array}$ & & $\begin{array}{l}\$ 17,692 \text { (complication } \\
\text { post-TTLND) } \\
\$ 17,692 \text { (complication } \\
\text { post-redo LND) }\end{array}$ & $\begin{array}{l}\$ 5754 \text { (hematoma } \\
\text { requiring neck re- } \\
\text { exploration) } \\
\$ 15,404 \text { (chyle leak) }\end{array}$ \\
\hline Short-term & & $\begin{array}{l}\$ 2224.24 \text { (Unilateral temporary RLN } \\
\text { injury) } \\
\$ 867.77 \text { (temporary } \\
\text { hypoparathyroidism) }\end{array}$ & & $\begin{array}{l}\$ 6318 \\
\text { (short-term complication } \\
\text { post lobectomy) }\end{array}$ & $\begin{array}{l}\$ 564 \text { (temporary vocal } \\
\text { cord palsy } \\
\text { including consultation, } \\
\text { laryngoscopy } \\
\text { and speech therapy) } \\
\$ 863 \text { (temporary } \\
\text { hypoparathyroidism } \\
\text { including follow-up } \\
\text { visits, blood tests } \\
\text { and medications) }\end{array}$ \\
\hline
\end{tabular}

(Continued) 
Table 5 (Continued).

\begin{tabular}{|c|c|c|c|c|c|}
\hline & $\begin{array}{l}\text { Lin et al }(2020 \text {, } \\
\text { Australia) }\end{array}$ & White et al $(2020, \text { USA })^{24}$ & $\begin{array}{l}\text { Oda et al } \\
(2017, \text { Japan })^{23}\end{array}$ & $\begin{array}{l}\text { Venkatesh et al } \\
(2017, \text { USA })^{22}\end{array}$ & $\begin{array}{l}\text { Lang et al } \\
(2015, \mathrm{HK})^{21}\end{array}$ \\
\hline Long-term & & $\begin{array}{l}\$ 27,874.28 \text { (Bilateral permanent RLN } \\
\text { injury) } \\
\$ 6623.08 \text { (Unilateral permanent RLN } \\
\text { injury) }\end{array}$ & & $\begin{array}{l}\$ 16,|2| \\
\text { (long-term complication } \\
\text { post lobectomy) }\end{array}$ & $\begin{array}{l}\$ 10,367 \text { (permanent } \\
\text { vocal cord palsy } \\
\text { including } \\
\text { consultations, } \\
\text { laryngoscopy, } \\
\text { speech and } \\
\text { medialization) }\end{array}$ \\
\hline \multicolumn{6}{|c|}{ Distant metastasis } \\
\hline Treatment & & $\begin{array}{l}\$ 60,196 \text { (initial) } \\
\$ 35,189 \text { (ongoing) }\end{array}$ & & & \\
\hline
\end{tabular}

Notes: All costs are costs mentioned in the original papers. Inflation has not been applied.

Abbreviations: USA, United States of America; AS, active surveillance; RAI, radioactive iodine; TSH, thyroid stimulating hormone; US, ultrasonography; FNA, fine needle aspiration; CT, computed tomography; L-thyroxine, levothyroxine; Ca, calcium; vit. D, vitamin D; PD, paratracheal dissection; TT, total thyroidectomy; CND, central neck dissection; CT, complete total thyroidectomy; MND, modified radical neck dissection; LND, lymph node dissection.

a different AS strategy according to age would be required in terms of not only tumor biological characteristics but also cost-effectiveness.

Our study has some limitations. Although we used the systemic method for searching the literature, there was a lack in the number of papers selected. In addition, among the five papers, two papers did not even construct the CEA model. Hence, it is difficult to make a clear conclusion about CEA for AS of PTC. In addition, the aforementioned studies almost used retrospective data. This limitation could be improved through accumulation of research about thyroid cancer CEA, especially in a prospective cohort population in the future. Recently, a Korean multicenter prospective study of AS or surgery (KoMPASS) has been initiated. ${ }^{30}$ The collection of adequate data and development of a CEA model will provide a better understanding of the costeffectiveness of AS and ES in Korea.

\section{Acknowledgments}

The literature search was supported and conducted by Na Jin Kim of the Medical Library at The Catholic University of Korea, Seoul, Republic of Korea. We would like to thank Editage (www.editage.co.kr) for English language editing.

\section{Author Contributions}

Han-sang Baek mainly designed the study and wrote the review. Chul-Min Kim and Dong-Jun Lim supervised the study and are corresponding authors. All authors contributed to data analysis, drafting or revising the article, gave final approval of the version to be published, agreed to the submitted journal, and agree to be accountable for all aspects of the work.

\section{Author Declaration}

A portion of this study was presented in abstract form at the AOCE-SICEM 2020 (Asia Oceanian Congress of Endocrinology and Seoul International Congress of Endocrinology and Metabolism 2020) in Seoul, Korea.

\section{Funding}

This research was supported by a grant from the Korea Health Technology R\&D Project through the Korea Health Industry Development Institute (KHIDI), funded by the Ministry of Health \& Welfare, Republic of Korea (Grant numbers: HC19C0481, HC19C0215).

\section{Disclosure}

The authors declare that they have no conflicts of interest for this work.

\section{References}

1. Yi HS, Chang JY, Kim KS, Shong M. Oncogenes, mitochondrial metabolism, and quality control in differentiated thyroid cancer. Korean J Intern Med. 2017;32(5):780-789. doi:10.3904/ kjim.2016.420

2. Hong S, Won Y-J, Park YR, et al. Cancer statistics in Korea: incidence, mortality, survival, and prevalence in 2017. Cancer Res Treat. 2020;52 (2):335-350. doi:10.4143/crt.2020.206

3. Davies L, Welch HG. Current thyroid cancer trends in the United States. JAMA Otolaryngol Head Neck Surg. 2014;140(4):317-322. doi:10.1001/jamaoto.2014.1

4. Ito Y, Miyauchi A, Kihara M, Higashiyama T, Kobayashi K, Miya A. Patient age is significantly related to the progression of papillary microcarcinoma of the thyroid under observation. Thyroid. 2014;24 (1):27-34. doi:10.1089/thy.2013.0367

5. Ahn HS, Kim HJ, Welch HG. Korea's thyroid-cancer "epidemic"screening and overdiagnosis. $N$ Engl $J$ Med. 2014;371 (19):1765-1767. doi:10.1056/NEJMp1409841 
6. Cho SJ, Suh $\mathrm{CH}$, Baek JH, et al. Active surveillance for small papillary thyroid cancer: a systematic review and meta-analysis. Thyroid. 2019;29(10):1399-1408. (1557-9077 (Electronic)). doi:10.1089/thy.2019.0159

7. Kwon H, Jeon MJ, Kim WG, et al. A comparison of lobectomy and total thyroidectomy in patients with papillary thyroid microcarcinoma: a retrospective individual risk factor-matched cohort study. Eur J Endocrinol. 2017;176(4):371-378. (1479-683X (Electronic)). doi:10.1530/EJE-16-0845

8. Gupta N, Verma R, Dhiman RK, Rajsekhar K, Prinja S. Costeffectiveness analysis and decision modelling: a tutorial for clinicians. J Clin Exp Hepatol. 2020;10(2):177-184. doi:10.1016/j. jceh.2019.11.001

9. Whitehead SJ, Ali S. Health outcomes in economic evaluation: the QALY and utilities. Br Med Bull. 2010;96(1):5-21. (1471-8391 (Electronic)). doi:10.1093/bmb/ldq033

10. Bertram MY, Lauer JA, De Joncheere K, et al. Cost-effectiveness thresholds: pros and cons. Bull World Health Organ. 2016;94 (12):925-930. doi:10.2471/BLT.15.164418

11. Choi MJ, Kang SO, Oh JJ, Park SB, Kim MJ, Cheong HJ. Costeffectiveness analysis of 13-valent pneumococcal conjugate vaccine versus 23-valent pneumococcal polysaccharide vaccine in an adult population in South Korea. Hum Vaccin Immunother. 2018;14 (8):1914-1922. doi:10.1080/21645515.2018.1456602

12. Lee D, Shin HY, Park SM. Cost-effectiveness of antiviral prophylaxis during pregnancy for the prevention of perinatal hepatitis B infection in South Korea. Cost Eff Resour Alloc. 2018;16:6. doi:10.1186/ s12962-018-0088-9

13. Yun JW, Choi MJ, Shin GS, et al. Cost-effectiveness of influenza vaccine strategies for the elderly in South Korea. PLoS One. 2019;14 (1):e0209643. doi:10.1371/journal.pone.0209643

14. Neumann PJ, Cohen JT, Weinstein MC. Updating costeffectiveness-the curious resilience of the \$50,000-per-QALY threshold. $N$ Engl J Med. 2014;371(9):796-797. doi:10.1056/NEJMp140 5158

15. Garrison LP Jr, Pauly MV, Willke RJ, Neumann PJ. An overview of value, perspective, and decision context-A health economics approach: an ISPOR special task force report [2]. Value Health. 2018;21(2):124-130. doi:10.1016/j.jval.2017.12.006

16. Boccuzzi SJ. Indirect health care costs. In: Weintraub WS, editor. Cardiovascular Health Care Economics. Contemporary Cardiology. Totowa, NJ: Humana Press; 2003. doi:10.1007/978-1-59259-398-9_5

17. Kuntz K, Sainfort F, Butler M, et al. Decision and Simulation Modeling in Systematic Reviews. Vol. 11. Rockville, MD: Agency for Healthcare Research and Quality; 2013.

18. Boeck JD, Verpoorten K, Luyten K, Coninx K. A comparison between decision trees and markov models to support proactive interfaces. Paper presented at: 18th International Workshop on Database and Expert Systems Applications (DEXA 2007); September 3-7' 2007; Regensburg.
19. McCabe C, Dixon S. Testing the validity of cost-effectiveness models. Pharmacoeconomics. 2000;17(5):501-513. doi:10.2165/ 00019053-200017050-00007

20. Chiou CF, Hay JW, Wallace JF, et al. Development and validation of a grading system for the quality of cost-effectiveness studies. Med Care. 2003;41(1):32-44. doi:10.1097/00005650-200301000-00007

21. Lang BHH, Wong CKH. A cost-effectiveness comparison between early surgery and non-surgical approach for incidental papillary thyroid microcarcinoma. Eur $J$ Endocrinol. 2015;173(3):367-375. doi:10.1530/EJE-15-0454

22. Venkatesh S, Pasternak JD, Beninato T, et al. Cost-effectiveness of active surveillance versus hemithyroidectomy for micropapillary thyroid cancer. Surgery. 2017;161(1):116-126. doi:10.1016/j. surg.2016.06.076

23. Oda H, Miyauchi A, Ito Y, et al. Comparison of the costs of active surveillance and immediate surgery in the management of low-risk papillary microcarcinoma of the thyroid. Endocr J. 2017;64 (1):59-64. doi:10.1507/endocrj.EJ16-0381

24. White C, Weinstein MC, Fingeret AL, et al. Is less more? A microsimulation model comparing cost-effectiveness of the revised american thyroid association's 2015 to 2009 guidelines for the management of patients with thyroid nodules and differentiated thyroid cancer. Ann Surg. 2020;271(4):765-773. doi:10.1097/SLA.00000 00000003074

25. Lubitz CC, De Gregorio L, Fingeret AL, et al. Measurement and variation in estimation of quality of life effects of patients undergoing treatment for papillary thyroid carcinoma. Thyroid. 2017;27 (2):197-206. doi:10.1089/thy.2016.0260

26. Lin JF, Jonker PKC, Cunich M, et al. Surgery alone for papillary thyroid microcarcinoma is less costly and more effective than long term active surveillance. Surgery. 2020;167(1):110-116. doi:10.1016/ j.surg.2019.05.078

27. Kim TY, Shong YK. Active surveillance of papillary thyroid microcarcinoma: a mini-review from Korea. Endocrinol Metab. 2017;32 (4):399-406. doi:10.3803/EnM.2017.32.4.399

28. Lohia S, Hanson M, Tuttle RM, Morris LGT. Active surveillance for patients with very low-risk thyroid cancer. Laryngoscope Investig Otolaryngol. 2020;5(1):175-182. doi:10.1002/lio2.356

29. Oh HS, Ha J, Kim HI, et al. Active surveillance of low-risk papillary thyroid microcarcinoma: a Multi-Center Cohort Study in Korea. Thyroid. 2018;28(12):1587-1594. doi:10.1089/thy.2018.0263

30. Jeon MJ, Kang YE, Moon JH, et al. Protocol for a Korean Multicenter Prospective Cohort Study of Active Surveillance or Surgery (KoMPASS) in papillary thyroid microcarcinoma. Endocrinol Metab. 2021;36(2):359. (2093-5978 (Electronic)). doi:10.3803/EnM.2020.890

31. Health Insurance Review \& Assessment Service (HIRA). 2011 Medical Economic Evaluation Guideline; 2016. Available from: http://www.hira.or.kr/cms/participation/05/07/_ icsFiles/afieldfile/ 2013/04/01/3.pdf. Korean.

\section{Publish your work in this journal}

Cancer Management and Research is an international, peer-reviewed open access journal focusing on cancer research and the optimal use of preventative and integrated treatment interventions to achieve improved outcomes, enhanced survival and quality of life for the cancer patient.
The manuscript management system is completely online and includes a very quick and fair peer-review system, which is all easy to use. Visit http://www.dovepress.com/testimonials.php to read real quotes from published authors. 